\title{
Policy Coherence and Mandate Overlaps as Sources of Major Challenges in Public Sector Management in Nigeria
}

\author{
Noel Ihebuzor ${ }^{1}$, Damiete O. Lawrence ${ }^{2}, \&$ Anthony Wakwe Lawrence ${ }^{3}$ \\ ${ }^{1}$ Evidentis Development Associates (Independent education and development consultancy), Abuja, Nigeria \\ ${ }^{2}$ Ph.D. Student in Management, Rivers State University, Port Harcourt, Nigeria \\ ${ }^{3}$ Community Inter-Relations and Conciliation Initiative - CIRCI (Non-governmental Organization) Port \\ Harcourt, Nigeria \\ Correspondence: Dr. Noel Ihebuzor, Evidentis Development Associates, Ndako, 900107, Abuja, Nigeria.
}

Received: November 16, 2020

Accepted: December 8, 2020

Online Published: December 18, 2020

doi:10.5539/ibr.v14n1p68

URL: https://doi.org/10.5539/ibr.v14n1p68

\begin{abstract}
Policies are management instruments that organizations employ to ensure their stakeholders and others understand their guiding principles. This paper examined the importance and impacts of policy coherence, mandate overlaps and policy management towards achieving policy effectiveness. The authors examined some extant development policies in Nigeria for policy coherence and assessed some agencies that implement these policies for mandate overlaps and mandate clarity/exclusiveness. To reduce policy incoherence and mandate overlaps, the paper recommended that policy makers should consult widely to understand all the issues involved and use multi-sector teams to ensure the development of effective policies that are robust in nature. Finally, it canvassed that policies be reviewed or evaluated from time to time to strengthen identified areas of weaknesses and enhance their effectiveness.
\end{abstract}

Keywords: policy-incoherence, mandate-overlap, policy-effectiveness, public-policy

\section{Introduction}

States and political or administrative units often promulgate guidelines and official guidance as to how matters under their political and administrative purviews are to be managed. Such guidelines and guidance which normally have the force of law are best described as policies.

Policies are management instruments that organizations employ to ensure their stakeholders and others understand their guiding principles. Policies are usually clear simple statements stating how the organization intends to operate. However, some policies may contain several chapters, headings and sub-units. Policies help in facilitating the basis for fundamental decision making. They help in goals and objectives setting and enhance reputation of the organization. They are good instruments to set clear priorities and implement specific or new interventions. They highlight and bring to everyone's consciousness new ideas that the organization wants to bring to the fore.

Government, private organizations, groups and individuals all make policies. Presidential/ executive orders, corporate private policies and parliamentary rules of order are all examples of policies (Jiliow, 2017). As stated above, public and private sectors all develop policies for effective operations. Most times, in the public sector, policies may be derived after a painstaking involvement of many stakeholders to get their buy-in.

Thus, in a country or a state or and administrative unit, one may come across things like a policy on agriculture, another on education and yet another on rural development. The purpose of such policies is to guide actions and also to provide framework to measure and assess the performance of civil servants who are usually called upon to implement such policies.

There is no gain-saying the fact, it is important that all the elements of a given policy hang together. This situation of amity and hanging together of different components of a given policy is what we shall define in this paper as policy coherence and it has advantages at several levels. It is also important that different policies across sectors and ministries are mutually reinforcing and supportive. We would, for instance, expect a policy in agriculture for instance to be supportive of a policy in rural development and vice versa. We would also be right 
to expect that a policy for science and technology should be reinforcing of a policy for fisheries development. Here again, we are dealing with policy coherence. Whereas the earlier example of policy coherence provided was within elements of a policy in term of their ideational integrity, the second is between element of different policies across sectors in terms of their organic and structural links. All the foregoing enables us to attempt a description of policy coherence as a situation where either different components of one policy or different policies existing in a political system possess or demonstrate qualities that are mutually reinforcing or supportive in such a way that there is harmony, agreement and cohesiveness within such policies as well as within the polity.

As we have shown in the preceding paragraphs, public policies owe their origins to the actions and processes of government or structures of government. When public policies and government programmes have gone through the process of development and ratification by the competent authorities in a country, their day to day implementation and monitoring are usually entrusted to ministries and government agencies, each established either through an act of parliament or by an edict depending on the style of democracy that is operative in the country. This is to say that each ministry and agency of government has specific mandate which very clearly defines and delineates its areas off authority and competence. Where there is no ambiguity in the phrasing of the mandates of a ministry, a parastatal or an agency of government, where the deliverables of such a unit are defined with clarity and focus, and the same principle applies across ministries and its agencies, mandate clarity is achieved. When mandate clarity is achieved, mandate overlaps are avoided. From here we can define mandate overlap as a situation where in the framing of the responsibilities of government agencies roles and responsibilities are so poorly defined as to create opportunities for redundancies in functions or duplication of deliverables. Mandate overlaps are bad for business as they result in huge wastages (human, material and financial), duplication of effort, unproductive turf battles, suspicion, politicking and progressive de-professionalization of government agencies.

\section{Rationale of the study:}

This study is driven by the need for all stakeholders to understand how policy incoherence and mandate overlaps affect policy effectiveness and resource use inefficiency.

\section{Method adopted for the study:}

The researchers selected some existing policies in related sectors in Nigeria and reviewed these to see to what extent their provisions are coherent and harmonious. Judgment on coherence and harmony were reached when there were clear indicators that the provisions were mutually reinforcing and were not in conflict. The same approach was adopted in examining the mandates of some public services agencies. Having examined these policies for coherence and the mandates of these agencies for overlaps, the researchers then went one step further to proffer solutions on how polices can generally be made more effective and on how incoherence and mandate overlaps can be reduced. The researchers hope to provide a framework for policy evaluation from time to time on the basis of the examination of policy coherences and mandates.

This paper will therefore examine some extant policies in Nigeria for policy coherence, assess the mandates of a few of the agencies who are called upon to implement these policies for mandate overlaps and mandate clarity/exclusiveness. In carrying out these tasks, the focus will be on unearthing and explicating the drivers of policy coherences and mandate clarity and exclusiveness (at the formulation and implementation levels). Finally, the paper will propose some strategies to improve on policy effectiveness.

\section{Literature Review}

The literature on policy making (Parsons, 2003; Davies et al 2000, and Hudson and Lowe, 2004) recognizes the vital role that the agenda of groups of persons assembled to produce a policy plays in policy formulation. The literature also recognizes the role that stakeholders' power and network play in policy formulation and policy implementation. In this sense therefore, policies arise out of negotiations that involve trade-offs and efforts to accommodate the interests and powers of different stakeholders.

Good Policies are developed when environmental, socio-economic, political, legal aspects among other factors are holistically considered. (Mazmanian \& Sabatier, 1999). Policy implementation, on the other hand, deals with those actions taken to translate policy decisions into observable outputs. It is "a problem solving activity that involves behaviours that have both administrative and political content" (Goggin, 1986, p.330). Mazmanian\& Sabatier $(1983,1999)$ identify important factors which influence policy implementation. These include available resources, economic capacities, and technological know-how and prescribed political rules. Other factors determining the effectiveness of policy implementation include policy suitability, capacity to implement, host 
environment receptivity, availability of support networks, political will and availability of funding (Sabatier, 1983). Also, factors very similar to those of programmatic attributes, will, skill and attributes of implementers, environment, organizational capacity, implementation behaviour and style were identified by Goggin (1986). But over and above all of these determinants of effective policy implementation remains that of policy coherence between policies in one sector and between policies across different sectors. Lack of coherence across policies results in waste, inefficiencies, tensions at the implementation level.

Parsons (2003); Davies et al.,(2000), and Hudson and Lowe (2004) identified the causes of policy incoherence as follows: insufficient stakeholder consultation at the conceptualization, drafting and review levels of policy, limited funding resulting in rushed work, ministerial ambitions, working in silos, timing of policy development, desire to reinvent the wheel, views of dominant members of the group, lifting and uncritical copying - bad policy transfer, and agenda of group assembled to develop policy for the public.

\section{Public Sector Management}

Management is commonly defined as the accomplishment of purpose through the organized effort of others (Wheelman and Hunger, 2010). The desire to lead right and understanding the nature to lead in order to achieve results are two different things - Often, we insinuate that managing the public sector is similar to managing the private sector. Chester (1938) indicated, the effectiveness of a corporation can be measured by the degree to which it accomplishes its purpose and its efficiency can be measure by whether individuals are willing to serve as workers, stakeholders, bankers and or customers - which implies that in a corporate setting, efficiency can be measured through profits (Bach, Terre and Vidal, 2020). Conversely, efficiency in the public sector can be measured not only in a stated purpose of the government body, but how that purpose is accomplished (Rechul and Wrona, 2018).

\section{Managing public sector can be measured in the following ways:}

1. Productivity or performance management: Bussim (2012) opined that performance or productivity management can be defined as a continuous process of improving individuals, team and organisational performance - it has to do with the fundamentals of any organization, since there are policies and guidelines meant to be followed in order to achieve its goals. Dailberl (2020) opined that. Productivity management is aimed at improving service delivery through effective and efficient application of resources; as well as policy adherence.

2. Resource management: Resource management can be defined as the ability to utilize resources in order to achieve intended goals - types of resources like: human resource, which is the most valuable resource to any organization, natural resource and finance. If the public policies are incoherence it will reflect on how poorly resources are being managed (Boselie, Harten and Veld, 2019). Resource management speaks volume to how, meaningful and harmonious policies coexist independently and inclusively.

With this, it is safe to suggest that public policy making is a rational process. A closer examination reveals that this is not always so. This is especially the case when strong personalities and new leadership weigh into the policy making process and seek to leave their imprints therein. It is not uncommon in the public service to find that each succeeding government and change in ministry leadership is often accompanied by attempts to change existing policies.

\subsection{Policy Incoherence}

Policy incoherence, which refers to a situation where two, or more policies or aspects and subsets within them fail to cohere or mutually reinforce or where two or more policies of government are discordant either in framing, intention or effect, can be very debilitating in public sector management. Let us provide examples of policy coherence/incoherence by looking at the provisions of Nigeria's National Policy on Education and Nigeria's Cultural Policy on the one hand and Nigeria's Policy for Integrated Rural Development (NPIRD) and Nigeria's National Economic Empowerment and Development Strategy (NEEDS), starting with the latter two. When one examines these two documents, that is NPIRD and NEEDS, by looking at their objectives, intentions and outcomes, one comes across a number of instances where Nigeria Policy for Integrated Rural Development (NPIRD) coheres with Nigeria's National Empowerment and Development Strategy (NEEDS) in terms of infrastructure provision, education and establishment of cottage industries. However, instances of incoherence begin to show up when one looks a bit more closely at implementation approaches and strategies with NEEDS leaning more towards a market driven ideology whereas NPIRD leans more to a government intervention approach. This type of incoherence or clash in prescriptions on implement action approaches is likely to send mixed messages when these policies are moved to the field level for actual implementation. 
Similar clashes and conflicts are also noticeable when it comes to education and cultural policies in Nigeria. Nigeria's language policy and cultural policy favor the development of all Nigerian languages and cultures but the National Policy on Education ends up with prescriptions and recommendations that give prominence to the three major languages (Hausa, Igbo and Yoruba) and English at the Federal level and some other nine languages at the state levels. It is worth restating here that Nigeria's cultural policy insists that all Nigerian languages and cultures must be developed for national development (Anyanwu, 2019) but incoherence begins to show up as implementation approaches favor the development of a limited set of languages and cultures. This assignment of disproportionate resources to some languages makes them to be considered as privileged or favored. It would thus appear that though the National policy recognizes the multiplicity and plurality of cultures and the need to preserve and promote all of these, actual practice appears not to be coherent with this larger policy recognition but is actually leading to situations where minority cultures and languages are being endangered. Policy prescription and implementation decisions are clearly in conflict in such situations and giving rise to incoherence. Such cases of lack of coherence as pointed out above could create problems, tensions and conflicts within the country and could indeed lead to a situation of denial of rights with attendant impacts on national development, work and efficiency in the public sector. Such policies must be quickly reviewed to instill greater coherence within them given the known benefits that accrue from policy coherence.

These include -

- Inter and intra-policy harmony

- ease of implementation

- reinforcement of effects and outputs/outcomes

- visible appeal

- stakeholders' buy-in

Some examples of policy incoherence

Policy incoherence is the opposite of policy coherence and it describes a situation where policies relating to a common issue, put out by the same authority or government or by different arms of the same government are either not mutually supporting each other or in extreme cases are in direct conflict.

The aspects of policy coherence and policy disharmony were critical factors during the formulation of the Sustainable Development Goals (SDG) drawn up by the United Nations and many scholars have extensively assessed the compatibilities and interdependencies of targets and goals using qualitative and quantitative approaches. Examples of such are the works on SDG4 and SDG16 (Lawrence A. W, Ihebuzor Noel and Lawrence D. O. 2020 a \& Lawrence A. W, Ihebuzor Noel and Lawrence D. O. 2020 b).

\subsection{Mandate Overlap}

As stated earlier, the other area of policy work of interest to us in this paper is the phenomenon of policy mandate overlaps. Policy mandate overlaps occur when by default in the phrasing of their enabling acts or decrees, two or more agencies in the public sector appear to have roles and deliverables that are either identical or similar such as to lead to major and glaring overlaps at the policy implementation level in their accountabilities and outputs. We argue that the key driver for this public policy problem is ultimately traceable to vague or ambiguous elements in the enabling decrees or acts of such agencies. We argue that where there is no ambiguity in the phrasing of the mandates of a ministry, or a parastatal or an agency of government, and where the deliverables of such a unit are defined with clarity and focus, and the same principle is applied consistently in the definition of roles, responsibilities and deliverables across ministries and its agencies, mandate clarity is achieved. When policy mandate clarity is achieved, policy mandate overlaps are avoided.

From here we can define policy mandate overlap as a situation where in the framing of the responsibilities of government agencies, roles and responsibilities are so poorly defined as to create opportunities for redundancies in functions or duplication of deliverables. Mandate overlaps are bad for business as they result in huge wastages (human, material and financial), duplication of effort, unproductive turf battles, suspicion, politicking and progressive de-professionalization of government agencies.

Let us remind ourselves of our earlier definition of policy mandate overlaps, providing appropriate illustrations of this phenomenon of policy mandate overlaps and then proceed to analyze how these could arise by examining how policies and mandates are formulated by relying on the earlier contributions of public sector policy scholars in the areas of policy formulation, policy streams, policy constituencies and issues dominance - (see Kingdon, Sabatier, Mazanian) 


\subsection{Examples of Policy and Mandate Overlaps Among A Number Of Federal Parastatals In Education In Nigeria}

\section{National Teachers' Institute (NTI)}

This was established 1976 by Decree No.7 of 1978 (Now Act No.7 of 1978) to provide courses of instruction leading to the Upgrade, Development and Professional certification of Nigerian Teachers as specified in the relevant syllabuses, using the Distance Learning System (DLS) of education delivery.

The objectives include:

- To truly professionalize the teaching profession at all levels;

- To curb the worrisome shortages of professional Teachers nation-wide; and

- To provide serving teachers the opportunity to further, upgrade / update their qualification and professional competence without necessarily leaving their jobs.

\section{National Commission for Colleges of Education}

The Commission which was established in 1989 by decree No 3 (now amended decree No.12 1993), lays down minimum standard for all programmes of teacher education at Nigeria Certificate in Education (NCE) level. In pursuit of its objectives, the Commission had standardized and continuously reviewed the curriculum of the Colleges of Education. After the laying down of minimum requirements for the Colleges of Education, the Commission had gone ahead to accredit their courses.

The Commission's core objectives include to:

- Make recommendations on the national policy necessary for the full development of teacher education and the training of teachers.

- Lay down minimum standards for all programmes of teacher education and accredit their certificates and other academic awards after obtaining thereof prior approval of the Honorable Minister of Education.

- Approve guidelines setting out criteria for accreditation of all Colleges of Education in Nigeria.

\section{Teachers Registration Council of Nigeria}

This is a regulatory Agency for teaching profession in Nigeria. Among its list of programmes and activities are the following:

- $\quad$ Execution of Mandatory Continuing Professional Education (MCPE) to guarantee that teachers keep abreast of developments in the theory and practice of the profession;

- Organization of Internship Schemes for fresh Education graduates to equip them with the necessary professional skills before licensing them for full professional practice; and

- Accreditation, monitoring and supervision of the courses and programmes of teacher training institutions in Nigeria to ensure that they meet national and international minimum standards. The institutions include the Colleges of Education, Faculties and Institutes of Education in Nigerian universities, Schools of Education in the Polytechnics, and the National Teachers Institute.

A quick review of the mandates of these agencies above, reveal clear cases of overlaps especially in the areas of teachers professional development in Nigeria.

A close look also at the mandates of the NERDC and the NINLAN shows up instances of mandate overlaps

Nigerian Educational Research Development Council (NERDC) and National Institute for Nigerian Languages (NINLAN)

NERDC is an implementing agency for policies of the Federal Ministry of Education concerning the Universal Basic Education (UBE) and other educational programmes nationwide. The core mandate of the Council is to conduct, promote and coordinate educational research, curriculum, book and language development programmes at all levels of education in Nigeria.

Among the numerous functions of NERDC are:

- Advise and implement all policies relating to languages;

- Coordinate language development projects throughout Nigeria and prepare an overall design for language research needs, both internally and through grants and subsidies to institutions, qualified 
agencies and organizations.

The Zonal Offices of NERDC ensures:

- Capacity Building for Teachers on the development of Instructional Materials from Local Resources for Core Basic Education Subjects (Primary School Level).

- Capacity building for teachers on the development of instructional materials from local resources for Core Basic Education Subjects (JSS level).

- Capacity building for teachers on the use and selection of instructional materials developed from local resources (Primary School level

\section{National Institute for Nigerian Languages}

Decree 117 (now Act No. 50 laws of the Federation of Nigeria 2004) set up Nigerian Institute for Nigerian Languages (NINLAN), in 1993 for the implementation of the language provisions of the National Policy on Education (NPE). The institute was principally set up as the apex institution for research, teaching, documentation and co-ordination of studies in Nigerian languages.

The functions include:

- Promoting the study and use of Nigerian languages;

- $\quad$ Exploring all relevant and available avenues, potential and resources to make the Institute -

(i) An active teaching and learning Centre for the study of Nigerian languages.

(ii) A resource Centre for specialized professional services to the public and private sectors of the Nigerian economy.

(iii) A Nigerian Centre for research into Nigerian languages.

It bears repeating once again that when the mandates of these agencies are subjected to close examination, we easily spot cases of overlaps such as those that exist in the mandates of the Teachers' Registration Council of Nigeria (TRCN) and the NTI in the area of teacher training (see the last bullet in the TRCN mandate for example). Our observations on mandate overlaps can be summarized as below:

The following Federal Ministry of Education Agencies have overlapping mandates -

1. NTI, NCCE, TRCN, NERDC and NINLAN all handle Professional Development of teachers irrespective of their core mandates. NTI has the core mandate of Professional Development of teachers through the distance learning Approach;

2. NINLAN's mandate overlaps with that of NERDC in the aspect of language development;

3. NCCE accredits courses of Colleges of Education as well as TRCN and here again, there are cases of overlaps.

Mandate overlaps are also most acutely noticeable in the management of basic education in Nigeria. Let us use the overlaps in the Mandates of the UBEC, NMEC and NCNE to illustrate further the issue of mandate overlaps by looking specifically at THE UBE ACT 2004 AND NMEC DECREE NO 17 OF JUNE 251990 (Structural and Mandate Overlap)

The National Commission for Mass Literacy, Adult and non-formal education, popularly called (NMEC) was established by Decree N0 171990 with the mandate to coordinate, regulate and monitor the implementation of non-formal education policies and programmes, with the vision to eradicate illiteracy in Nigeria. The Commission has its structure from Federal Ministry of Education, through NMEC to State Agencies for Mass Education (SAMEs) and the Local Government Adult Education Units (LGAEUs). The National Policy (NPE, 2013) further stated that adult and non-formal education provides functional basic education for adults and youths who have never had the advantage of formal education or who left school too early. The target groups include migrant folks, Alma-Jiri pupils, illiterate and semi-literate adults, youths and adolescent; persons who left the formal school system early and are now willing to come back and continue schooling; and other categories of disadvantaged groups; who are unable to have access to the conventional educational programmes to cater for their particular or peculiar needs and circumstances. It also provides remedial and lifelong education for youths and adults who did not complete secondary education and in-service, vocational and professional training for different categories of workers and professionals in order to improve their skills

Under the Universal Basic Education (UBE) programme, provision is also made for Mass literacy, Adult and Non-formal Education. 
The UBE Act (2004) states that "Universal Basic Education" means, early childhood care and education, the nine years of formal schooling, adult literacy and non-formal education, skills acquisition programmes and the education of special groups such as nomads and migrants, girl-child and women, Almajiris, street children and disabled groups.

The UBE Act (2004) provides for the establishment of the Universal Basic Education Commission (UBEC), the Universal Basic Education Boards (SUBEBs) of each state and Local Government Education Authorities (LGEAs) in each of the 774 local government areas in Nigeria. The implementing agencies of the UBE programme are the Universal Basic Education Commission (UBEC), National Mass Education Commission (NMEC) and the National Commission for Nomadic Education (NCNE).

The Universal Basic Education Commission is empowered by its Act to coordinate the implementation of the UBE programme at the federal, state and local government levels while NMEC has the responsibility to coordinate the implementation of policies and programmes of Mass Literacy, Adult and Non-Formal Education nationwide, as provided in its enabling law and the national policy on education.

Therefore, the UBE Act 2004 and NMEC Decree N0. 17 of 1990 recognize the implementation of Mass Literacy, Adult and Non-Formal Education under different structures.

Policy and mandate overlaps thus exist among a number of these federal Parastatals in Education in Nigeria. These include as we have shown the UBEC, TRC, NTI, NCNE, NMEC, NCCE, NERDC, NINLAN etc. Most of these agencies exhibit clear instances of overlaps and lack of clarity in mandates. Such overlaps create problems of focus, of effective resource utilization, of proper accountability and implementation coordination.

Solutions would include clear division of labor, proper role assignment among these agencies and regular consultations to avoid wastes.

\section{Drivers of mandate overlaps}

Politics and political power-Parsons (2003) who recognizes the important role that politics, especially perceived stakeholders' power and interest can play in framing choices and influencing choices and decisions)

\section{Effects of mandate Overlaps}

\section{Duplication of functions and mandates}

Non-formal education is now being provided by both the UBEC and the NMEC. This is duplication and this results in wastes and inefficiencies

2. Confusion at the implementation levels in the states. UBEC functions at the state level through structures known as State Basic Education Boards which are headed by Directors. In the same states, the NMEC has its own corresponding agencies known as State Agencies for Mass Education (SAMEs) also headed by Directors appointed by the Governors. Both SAME and UBEBs have responsibilities for adult education, a situation that leads to wastes, unnecessary frictions and inefficiency.

\section{Funding}

In terms of funding, there is a UBE $2 \%$ consolidated revenue fund meant to be used by the three agencies in funding their respective activities, but this fund is domiciled with UBEC only, who has the sole powers to manage and disburse the fund. NMEC, NCNE and their state agencies have no powers over the money. They can only access the fund if they provide counterpart to the tune of 50\% of the cost of any project they wish to embark upon.

\section{Poor administration of NFE}

From the structural arrangement, you find out that the Universal Basic Education has three parallel structures, each headed by an independent executive secretary. Each executive secretary is autonomous in terms of authority and administration. There is no effective central coordination and regulation of UBE programmes. Decision-making is at different levels and reporting of programmes and activities are done independently. Therefore, there is no proper coordination, no effective planning and evidence of poor reporting system. The UBEC does not have accurate data on those who drop out of the formal system, which are provided opportunity under the non-formal education system and vice versa.

Other effects of mandate overlaps include:

- Unclear definition of responsibilities;

- Breeding inefficiency and redundancy; 
- Encouragement of misplaced priorities; and

- Increased inter-agency conflicts

\section{Some Policy Improvement Strategies}

It is clear that good policy should be integrated and well aligned with all the internal factors as well as being well aligned to effectively manage external factors that may impact on the organization achieving its core goals and objectives. As can be seen, a good policy has to have the following qualities: be effective, be efficient, be professionally developed, be clear and concise and be unique.

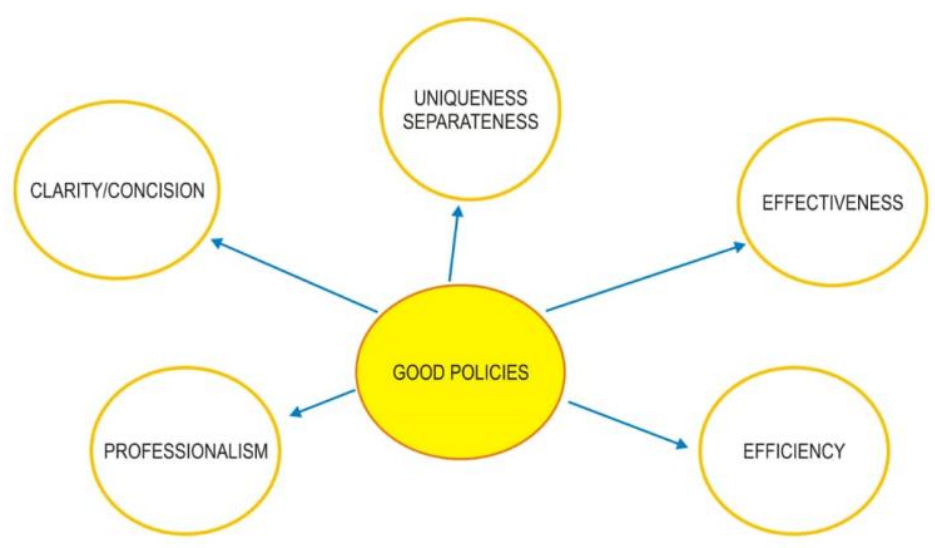

Figure 1. Indicators of Good Policies

Source: Researchers' (2020).

Every new leader has the temptation or zeal to go beyond current standards and make his mark during his tenure. This is done through modification of existing policies even when the benefits of upholding policy continuity, especially for policies that effectively drive sustainable organizational progress are in place and are functional. A major cause of policy incoherence and mandate overlap is due to this problem.

However such efforts at policy renovation must be done with care to ensure that such changes in policies and procedures do not constitute adverse effects or result in massive project abandonments. These issues of drastic policy reversals occur when there are hostile leadership changes or takeovers and it is mainly in political settings. Such leaders are sentimentally tempted to spend resources just to discredit the past leadership at some expense to organizational overall performance. However, despite the need to maintain policy continuity as much as possible, new leaders and even older ones need to evaluate their policies, strategies and procedures from time to time towards making continuous improvements.

It is for these reasons that we propose the process below as a way of evaluating every organization and ensuring continuous improvement in organization's policy effectiveness. By policy effectiveness here, we mean the enactment of clear and implementable policies with high degrees of internal coherence and synergy, two qualities which then make for efficiency and effectiveness at the implementation level. This process of effective policy must involve continuously seeking out and identifying opportunities and strengths and agreeing best ways to enhance their potentials. The other part of the process is also to scan for threats and identify organizational weaknesses and agree best ways to control or eliminate the impacts of such on the organization. 


\section{General principle to enhance policy effectiveness}

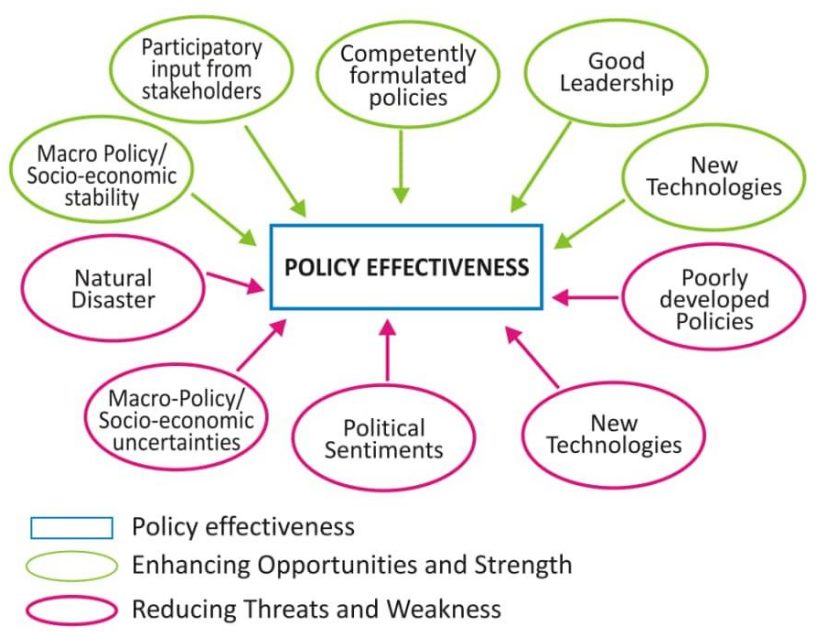

Figure 2. shows strategies to enhance policy effectiveness

Source: Researchers' (2020)

The above figure elucidates some of such favourable and unfavourable factors and strategies to ensure organizational policy effectiveness.

In addition to policy evaluation from time to time towards identifying levels of policy coherence and mandate overlaps within a system, organizations and their policy makers are expected to formulate policies that will explore and enhance favourable factors for improved success and profitability. On the other hand, unfavourable conditions will require formulation of policies to reduce the negative impacts on such organizations.

Policies, as we have said earlier, are management instruments that can be used to effectively manage organization to deliver on set goals and objectives. However, there are factors that affect their effectiveness: some may be unforeseen uncertainties that can be occasioned by natural disasters like the recent Corona Virus (COVID-19) pandemic or earthquake etc. Others might be as a result of changes in macro-policies at the national level, resulting in organizations adapting to surviving within the new regulatory environment. Such changes might not favour an organization while others would favour its growth and profitability. Effective scanning of the organization's environment proactively, will enable an organization understand threats and opportunities and develop measures, strategies and where necessary proactively put in place new policies that are more robust and can better protect the organization and stabilize it in case of eventualities.

Given the inefficiencies that policy incoherence brings about, it is important that efforts are made at the policy framing levels to minimize these. Such efforts would involve the following: making adequate provision of resources including time, to avoid rushing through a new policy. The more time that is set aside, the more there will be opportunities to avoid duplications by reviewing existing policies in the area under concern and to fully understand the scope and extent of their provisions. The second thing that needs to be done is to set up a broad policy drafting team and to insist that this team holds adequate levels of consultations with other stakeholders, when all the drafting has been done. It is vital to scan the emergent policy for overlaps and inconsistencies with extant policies. The final step is to subject the draft to detailed critique before rushing to press

\section{Conclusion}

Where policies are effectively developed, then there is less likelihood that they will not be effective. Policy makers must have in-depth knowledge of the organization for which they want to make a policy and the issues they are handling. They should consult widely to understand all the issues involved, they must get the buy-in of top level management of the organization who will drive the policy. A multi-sector team is more likely to develop more effective policies that are robust and such team should consult widely with all other related arms to avoid duplication of duties.

Policy incoherence will be avoided if competent persons are drafted to facilitate their formulation and mandate overlaps can be managed by the merging of agencies; and clearly define their responsibilities.

On the areas of focus in this paper, we recommend as follows: 
1. The implementing bodies of the Universal Basic Education - (UBEC. NMEC and NCNE) should be merged under one administrative structure headed by one Executive Secretary. The UBEC, NMEC and NCNE could serve as departments headed by Directors. There should be SUBEB for formal basic education and SUBEB for the non-formal basic education, under a federal structure. The state agencies should be scrapped or converted as recommended. This will enhance effective administration, synergy and funding.

2. Alternatively, the various agencies could still retain their independence, but the non-formal aspect of the UBE should be removed and added to NMEC and $50 \%$ of the UBE $2 \%$ consolidated revenue fund allocated to NMEC for the administration, coordination and regulation of NFE in Nigeria.

Policies are aimed at addressing issues of importance and it should be realistic enough and easy to develop the other steps towards policy implementation (developing procedures, tactics and activities). Policies are usually for the long-term use; however, even when short-term goals are in view, the policy formulation should consider its applicability and effects on long-term goals of the organization.

If policy development is driven by need and not just political or sentimental reasons then policies made are likely not to be changed frequently, which in itself will confuse the stakeholders.

Sometimes, policies will need to be changed as a way to adapt to adverse changes in the environment or mitigating new information that negatively affects the organization. At other times, policy can be changed as a way to further explore opportunities or enhance advantages as organization strengths etc.

Finally, policies implementation should be reviewed or evaluated from time to time to strengthen any identified area of weaknesses and enhance its effectiveness.

\section{References}

Aghion, P., \& Durlauf, S. (2009). From Growth Theory to Policy Design. The International Bank for Reconstruction and Development / the World Bank, Commission on Growth and Development (Working Paper Number 57).

Alcock, A. E., Taylor, B, K., \&Welton, J. M. (1979). The future of Cultural minorities. London, MacMillan Press. https://doi.org/10.1007/978-1-349-04262-3

Ali, I. J. (2017). Policy, Difference Between Policy and Procedure, Types of Policy, Characteristics of Policy, Policy Analysis Approaches, Stages of Policy Cycle \& Policy Making Process.

Anyanwu, C. (2019). Nigeria's Cultural Policy and The Needs of the Performing Arts. International Review of Humanities Studies, 4(2), 717-727. https://doi.org/10.7454/irhs.v4i2.177

Bach, A., Terre, M., \& Vidal, M. (2020). Symposium review: Decomposing efficiency of milk production and maximizing profit. Journal of diary science, 103(6). https://doi.org/10.3168/jds.2019-17304

Boselie, P., Harten, V. J., \& Veld, M. (2019). A human resource management review on public management and public administration research. Public Management Review, 1-18. https://doi.org/10.1080/14719037.2019.1695880

Browne, A., \& Wildarsky, A. (1999). Implementation as mutual adaptation. In T. Miyakawa (Ed.), The Science of Public policy, London, Routledge (Taylor \& Francis group), Ch3, pp. 57-79.

Bussim, M. (2012). Perfomance Mangment - how to get it right. 21 Century Pay Solutions Group. Rosebbank Johannesburg, An evaluation of the effectiveness, page 7. Journal of Management and Marketing Research.

Chester, I. B. (1938). The Functions of the Executive. Cambridge, Mass.: Harvard University Press

Dailberl, C. F. (2020). Systematic literature review: Approaches for improving service productivity from a network perspective. Driving Network Service Productivity, pp.49-89. https://doi.org/10.1007/978-3-658-29580-6_3

Davies, H. T., Nutley, S. M., \& Smith P. C. (2000). What works? Evidence-based policy and practice in the public service. Bristol, the Policy Press. https://doi.org/10.1332/policypress/9781861341914.001.0001

Dolowitz, D., \& Marsh, D. (2000) Learning from abroad: the role of policy transfer in contemporary policy-making, Governance. An international journal of policy and administration, 13(1), 5-21. https://doi.org/10.1111/0952-1895.00121

Evans, M. (1999). Policy transfer networks and collaborative government: the case of social security fraud. Public Policy and Administration, 14(2), 30-48. https://doi.org/10.1177/095207679901400204 
Federal Government of Nigeria [FGN] (2004). UBE Act establishing the Universal Basic Education Commission. Abuja, Nigeria.

Federal Government of Nigeria [FGN]. (1981). National Policy on Education, NERDC Pres. Lagos, Nigeria.Federal Government of Nigeria [FGN] (2013). National Policy on Education (6th ed.). NERDC Press, Lagos, Nigeria.

Fishman, J. (1993). Ethnolinguistic democracy - varieties, degrees and limits. Language International, 5(1), $11-1$.

Gabriel, J. M. O. (2018). Business Management: An indigenous standpoint. Nigeria: University of Port Harcourt Press.

Hanusch, M. (2012). The Doing Business Indicators, Economic Growth and Regulatory Reform. World Bank Policy Research Working Papers. 6176. https://doi.org/10.1596/1813-9450-6176

Hudson, J., \& Lowe, S. (2004). Understanding the Policy Process: analyzing welfare policy and practice. Bristol, The Policy Press.

Ihebuzor, N., Lawrence, A. W., Tamunomiebi, M. D., Lawrence, D. O., \& Lawrence, B. A. (2020). The Impacts of Violent Conflicts, Injustice and Weak Institutions on the Effective Delivery of the SDGs and Agenda 2030. International Journal of Innovative Research and Development, 9(7).

Jiliow, A. I. (2017). Policy, Difference Between Policy and Procedure, Types of Policy, Characteristics of Policy, Policy Analysis Approaches, Stages of Policy Cycle \& Policy Making Process. Malaysia.

Kelman, H. C. (1971). Language as an aid and barrier to involvement in the National system. In Rubin, J., \& Jernudd, B. H. (Eds.), Can language be planned? Hawaii, University of Hawaii Press.

Lawrence, A. W., Ihebuzor, N., \& Lawrence, D. O. (2020). a. Macro-Level Studies of Direct and Indirect Relationships between SDG 4 and the 16 SDGS. Modern Economy Scientific Research Publishing, 11. https://doi.org/10.4236/me.2020.116085

Lawrence, A. W., Ihebuzor, N., \& Lawrence, D. O. (2020). b. Comparative Analysis of Alignments between SDG16 and the Other Sustainable Development Goals. International Business Research, 13(10). https://doi.org/10.5539/ibr.v13n10p13

Lipsey, M. W. (1996). Key issues in intervention research: a programme evaluation perspective. American Journal of Industrial Medicine, 29, 298-302. https://doi.org/10.1002/(SICI)1097-0274(199604)29:4<298::AID-AJIM4>3.0.CO;2-L

Lundvall, B. Å. (2007). Innovation System Research and Policy: Where it came from and where it might go. Centre for Advanced Study (CAS). Norwegian Academy of Science and Letters, Oslo.

Malaysia, B. A. (1992). Speaking in Tongues, Implication of Multilingualism for Language Policy in Nigeria. Lagos, National merit Award Lecture.

Mazmanian, D. A., \& Sabatier, P. A. (1983). Implementation and Public policy. Scott, Foresman and Co., Glenview.

Mazmanian, D. A., \& Sabatier, P. A. (1999). A framework for analysis implementation. T. Miyakawa (Ed.), pp 97-128.

Meyers, R. A. (2013). Encyclopaedia of Complexity and Systems Science. Springer Science and Business Media New York, 45-3.

Parsons, W. (2003). Public Policy. Edward Elgar, Cheltenham, UK.Rubin J. and Jernudd B. H (eds). (1971). Can language be planned? Hawaii, University of Hawaii PressRechul, H. and Wrona, B. (2018). The Methods of Measuring the Efficiency of the Public Finance Sector. International Journal of New Economics and Social Science, 7, 39-49.

Wheelen T. L., \& Hunger, J. D. (2015). Concepts in strategies management and business policy (14th ed.). New Jersey, Prentice Hall.

\section{Copyrights}

Copyright for this article is retained by the author(s), with first publication rights granted to the journal.

This is an open-access article distributed under the terms and conditions of the Creative Commons Attribution license (http://creativecommons.org/licenses/by/4.0/). 